\title{
The Effect of Adding Steel Slag and Lime on The Engineering Properties of a Sandy Soil
}

\author{
Ayad Abdelmoula Mohammed, Mohammed Ali Abdalla Elsageer* \\ Department of Civil Engineering, Faculty of Engineering, Sirte University, Libya
}

DOI: https://doi.org/10.21467/proceedings.4.23

* Corresponding author email: drmohammedalsger@gmail.com

\begin{abstract}
Compaction is the process of mechanically densifying a soil which increase its density to meet engineering requirements. Unstable soils can create significant problems for pavements or structures, therefore soil stabilization techniques are necessary to ensure the good stability of soil so that it can successfully sustain the load of the superstructure especially in case of soil which are highly active, also it saves a lot of time and millions of money when compared to the method of cutting out and replacing the unstable soil. This research describes a study of the effect of adding steel slag and lime on the engineering properties of a sandy soil. A series of laboratory experiments have been implemented and varieties of samples were made by mixing steel slag and lime with soil. different percentages of steel slag and lime were used as stabilization materials. Test results show that adding steel slag and lime can improve the properties of compacted sandy soil, and has a great effect on the behavior of compaction of stabilized soil, the maximum dry unit weight increased gradually at the low addition ratios and the maximum increase occurred at steel slag and lime content equals to $25 \%$ and $15 \%$ respectively.
\end{abstract}

KEYWORDS: Steel Slag, Compaction, Sandy Soil

\section{Introduction}

The availability of build able land is fast drifting away each day due to scarcity of lands with good natural bearing capacity. This leads to construction of building on poor soils which eventually lead to structural foundation failures. It has become very imperative to improve soil or the quality of grounds by the adoption of suitable improvement methods depending on the materials available . however, during soil or ground improvement, cost effectiveness is one of the major factors. Consequent upon this, there is paramount need to adopt the use of admixture during steel slag/soil improvement or stabilization. However, steel slag which is a waste product from steel production could replace some proportions of sand/soil. This admixture not only replaces some proportions of soil for cost effective soil improvement. this review work exposes those qualities and applications that make steel slag a good replacement or not during mixing with soil, to find out how improvement and for a more economic approach for stabilization soil. The present review also gives researchers and geotechnical engineering a clue on the application of steel slag and the limit for its usage. Different

(C) 2018 Copyright held by the author(s). Published by AIJR Publisher in Proceedings of First Conference for Engineering

Sciences and Technology (CEST-2018), September 25-27, 2018, vol. 2.
This is an open access article under Creative Commons Attribution-NonCommercial 4.0 International (CC BY-NC 4.0)

A iR license, which permits any non-commercial use, distribution, adaptation, and reproduction in any medium, as long as the original work is properly cited. ISBN: 978-81-936820-6-7 
methods can be used to improve and treat the geotechnical properties of the problematic soils (such as strength and the stiffness) by treating it in situ , these methods include dandifying treatments (such as compaction or preloading). The chemical stabilization of the soils (soft fine-grained soils) is very important for many of the geotechnical engineering applications such as pavement structures, roadways, building foundation, channel and reservoir linings, to avoid the settlement of soft soil.

Many materials and items discarded by organizations, companies and people have the potential to be reused for their original purposes or for new ones. Reuse discarded materials and items allows companies to get the most out of it. Additionally, reusing products conserves natural resources and saves valuable landfill space. Use of environment friendly materials in any industry is of paramount importance. limited waste landfill space, increasing cost of waste disposal in combustion facilities and landfills, depletion of the natural resources, and the need for sustainable development have all amplified the need to reuse the materials that were once regarded as wastes as substitutes for natural resources. In 2002, 50 million metric tons of steel slag was estimated to be produced worldwide ${ }^{[1]}$ and 12 million tons was estimated to be produced in Europe [2]. Currently, the world annual production of steel slag is estimated to range between 90-135 million metric tons. Approximately 15 to $40 \%$ of the $10-15$ million metric tons of steel slag generated in the United States in 2006 was not utilized [3] and a larger percentage of the 0.35-0.45 million metric tons of steel slag estimated by Akinwumi et al. ${ }^{[4]}$.

GGBS or GGBFS (Ground Granulated Blast Furnace Slag) is a waste product drawn by the rapid cooling of molten iron slag. It is obtained from steel manufacturing process. In order to make use of GGBS, an attempt has been made for adopting it in soil stabilization. From the previous studies, it is clear that the GGBS induces the strength of cement and is extensively used as cement additives. This can be implemented in the soil for stabilization.

Addition of these wastes in stabilization technique makes proper utilization of these wastes and solves the problem of disposal. Steel slag is a by-product produced during the conversion of iron ore or scrap iron to steel.

Numerous studies have been conducted by various researchers for the use of steel slag to improve the engineering properties of weak soils .

The use of steel slag has been established in a number of applications in the construction industry. Slag can be applied as a material in cement, as road base course material due to large bearing capacity and excellent in wear resistance [5] as aggregate material for the asphalt concrete mixture ${ }^{[6]}$ as fine and coarse aggregates in cement concrete mixture ${ }^{[7]}$ and as improvement weak soil due to high angle of internal friction and high particle density. Osinubi, et al. ${ }^{[8]}$ studied the effect of using Blast Furnace Slag (BFS) to stabilize a lateritic soil to be used as hydraulic barrier. It was observed that inclusion of BFS increased the CBR value to $10 \%$ of the soil treated with $9 \%$ BFS and it became suitable for the use as hydraulic barrier.

Proceedings of First Conference for Engineering Sciences and Technology (CEST-2018), vol. 2 
The Effect of Adding Steel Slag and Lime on The Engineering Properties of a Sandy Soil

Oormila and Preethi [?] examined the properties of black cotton soil stabilized using fly ash (FA) and Ground Granulated Blast Furnace Slag (GGBFS).Different percentages of FA and

GGBFS were added. They found that the stabilizers have significantly improved the index properties of the soil and to achieve the maximum CBR value, the soil was blended with $20 \%$ GGBFS.

Golakiya and Savani ${ }^{[10]}$ investigated the effect of Electric Arc Furnace Dust (EAFD) and Dolime fine addition on black cotton soil to improve geotechnical properties. Electric arc furnace dust generated during steel production and considered as hazardous waste. Dolomite stone is a type of lime stone and additive for slag formation. During the crushing process of Dolomite stone, fine particle is generated known as Dolime fine and regarded as industrial waste. They found that addition of 30\% EAF dust and 12\% Dolime to the black cotton soil had shown a good result.

Akinwumi [11] who studied soil improvement using electric arc furnace (EAF) steel slag. Various percentages of pulverized steel slag were applied to the soil. It was observed that pulverized steel slag improved the plasticity, uncured strength and drainage characteristics of the soil at the optimum percent of slag $6 \%$.

Biradar, et al. [12] investigated the effect of using Fly ash and Steel slag to stabilize clay soils. Fly ash and Steel slag were mixed at different percentages 0, 10, 20, 30, 40 and 50\% by weight of the soil to obtain the optimum percentage of admixture required. The study results showed that addition of steel slag and fly ash decreased the consistency limits and increased the CBR value of the soil.

\section{$1.1 \quad$ Objective}

The objective of the study is to improve the proctor compaction test properties of the soil, through the addition of steel slag and lime as stabilizers to become able to withstand the loads located

\section{Experimental Work}

Proctor compaction tests are conducted using equipment and procedures. The soil is brought to a desired moisture content and compacted in layers in the selected mold. After compaction, the moist unit weight and moisture content are determined and the dry unit weight calculated. These procedures are repeated at a sufficient number of moisture contents to establish a relationship between dry unit weight and moisture content at compaction. This data, when plotted, represents a curvilinear relationship known as the compaction curve or moisturedensity curve. The values of maximum laboratory dry unit weight ( $(\mathrm{d}$-max) and optimum moisture content are determined from the compaction curve.

\subsection{Materials}

\subsubsection{Water}

Tap water was used for mixing and increase moisture content. 


\subsubsection{Soil}

Soil was collected from Sirte and used in this research. The soil was stored in dry place and passed through U.S. sieves and the results of sieve analysis (D 6913) test are shown in Figure 1.

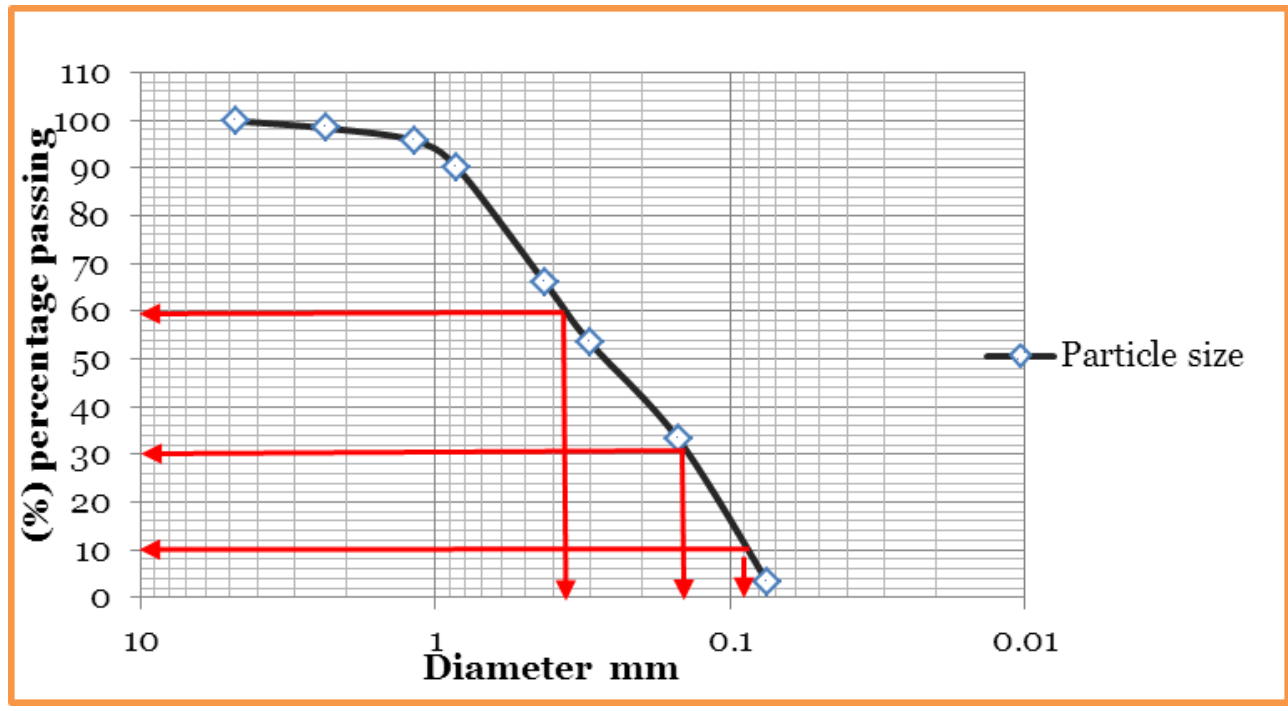

Figure 1: Particle Size Distribution of Tested Soil

According to the sieve analysis results and Unified Soil Classification System soil experimented in this work is classified as granular materials, and the type of soil is SP : sand poorly graded.

\subsubsection{Steel Slag - Blast Furnace Slag (GGBS) :-}

Steel slag was collected from Libyan iron and steel company (Misurata) and used in this research. Six ratio 5, 10, 15, 20, 25 and 30\%, by weight of the soil used. The steel slag samples were crushed to reduce its particle size down to less than $0.425 \mathrm{~mm}$.

\subsubsection{Lime}

Commercially available lime which was used in this study, passed through sieve No 200 and mixed with soil in varying percentages 5, 10, 15, 20, 25 and 30\%.

\subsection{Sample Preparation}

To prepare sand soil . it was first oven -dried at $105^{\circ} \mathrm{C}$ approximately 24 hours. Then, it was taken out of the oven and compacted. After that, $5000 \mathrm{gm}$ of these soil were taken and mixed with lime, steel slag in varying percentage 5, 10, 15, 20, 25 and 30\%. The lime and steel slag were passed through sieve No 200 before to be mixed with soil. 
The Effect of Adding Steel Slag and Lime on The Engineering Properties of a Sandy Soil

\section{Results and Discussion}

\subsection{Compaction Test on Non-Treated Soil}

Figure 2 shows the results of standard proctor test on the natural soil , which shows a typically shaped curve with a single peak, with maximum dry density of $1.95 \mathrm{~g} / \mathrm{cm}^{3}$ at optimum moisture content of $11 \%$.

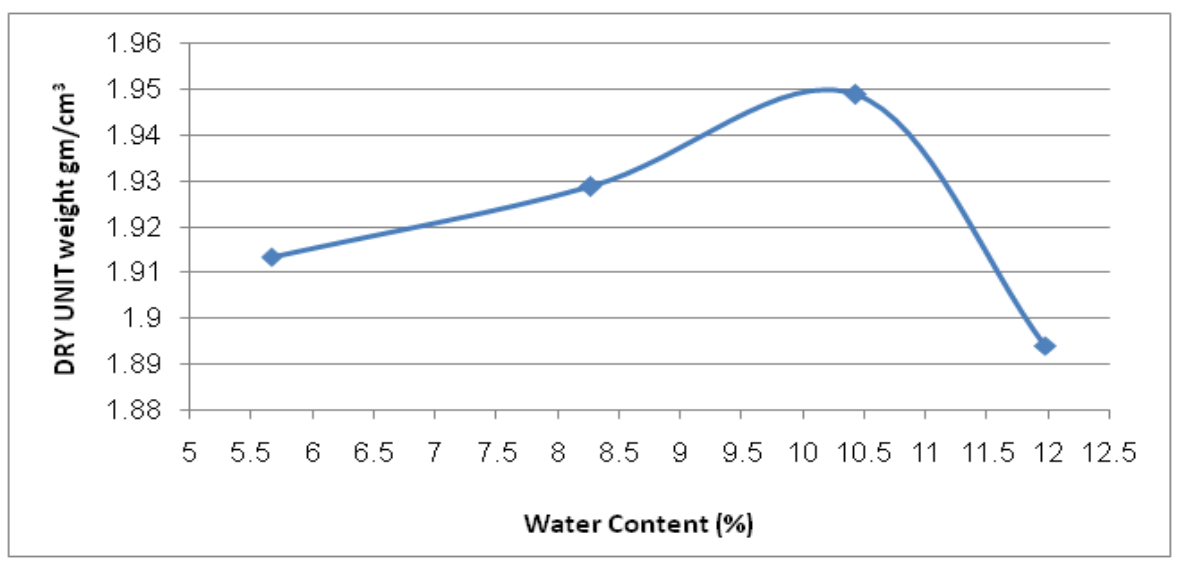

Figure 2: Standard Proctor Test Results on Natural Soil

\subsection{Standard Proctor Test on GGBS Treated Soil}

In order to investigate the effect of addition of steel slag on optimum water content and maximum dry unit weight of the selected soils, a series of standard proctor tests on GGBS treated soils 5, 10, 15, 20, 25 and 30\% GGBS content by weight of selected soil were conducted according to ASTM D(698). Selected soil was dried in a oven and mixed until uniform color was observed before compaction. Figure 3 shows the effect of replacing GGBS on the soil with the investigated percentages, which shows that at the beginning of GGBS replacement, the maximum dry unit weight increased gradually. The highest value of dry unit weight was obtained at GGBS content equal 25\%. On the contrary, increasing the GGBS content more than 25\% (GGBS>25\%) decreased the maximum dry unit weight of stabilized soil.

It is clear also from the figure that the optimum water content varied with GGBS content. The optimum water content fluctuated with the increase of GGBS content. This can be attributed to the change of surface area of treated soil than that in natural sandy soil.

\subsection{Standard Proctor Test on Lime Treated Soil}

Figure 4 shows the effect of adding Lime on compaction characteristics of the tested soil samples. it is clear that the effect of replacing five different percentage of lime to soil had nearly similar results, However, the replacement of lime to sandy soil was important to develop the behavior of stabilized soil. It also shows that at the beginning of replacing lime the maximum dry unit weight is almost stay the same, then the maximum dry unit weight was achieved at lime content equal $15 \%$ dry unit weight of stabilized soil then decreased by replacing more lime. 


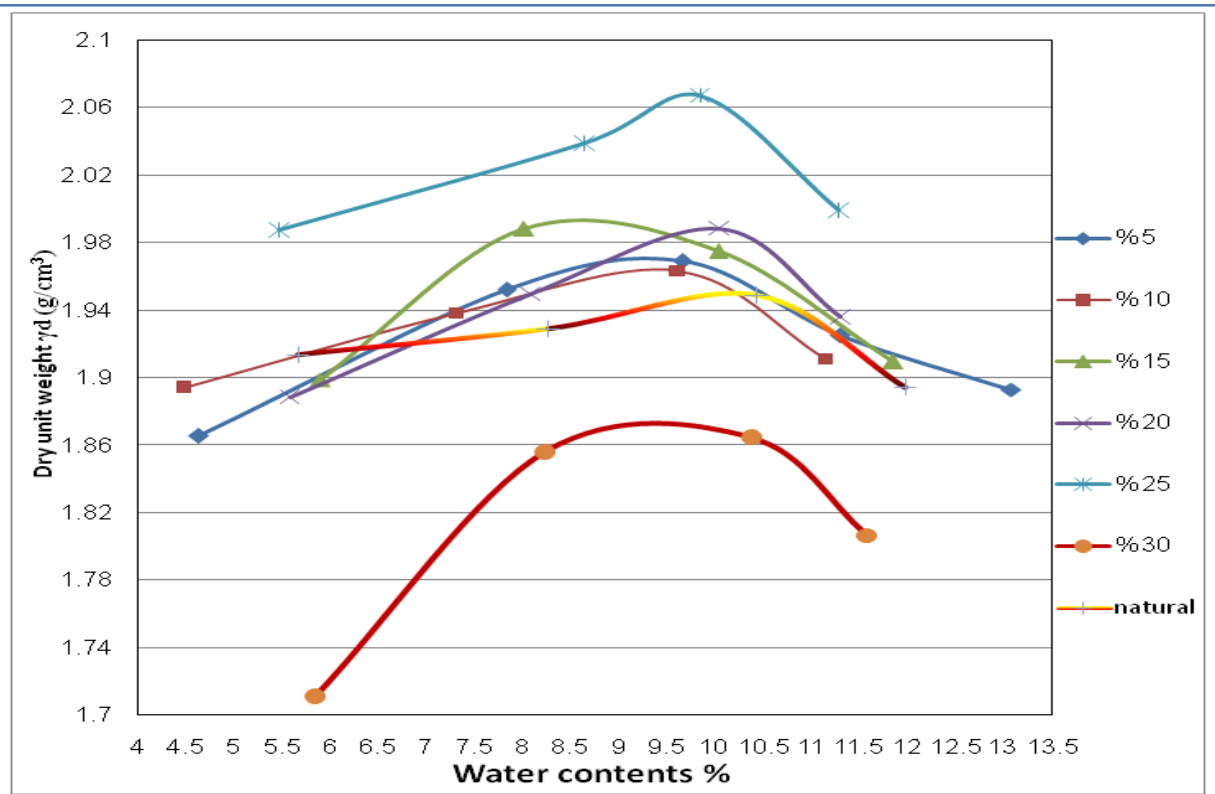

Figure 3: Standard Proctor Test Results on Soil With Various GGBS Content

It is also from the below result that the optimum water content varied with lime content. The optimum water content fluctuated with increasing of lime content. Figure 5 shows that the values of the max dry unit weight of soil increase with the increase of the both additives ( GGBS and lime) and the highest values of dry unit weight ( $\gamma \mathrm{dmax})$ is obtained at GGBS content equal to $25 \%$ and $15 \%$ for lime. Furthermore the replacement of GGBS has a marked effect on the increase of max dry unit weight of soil comparing with the replacement of lime at the different tested percentages.

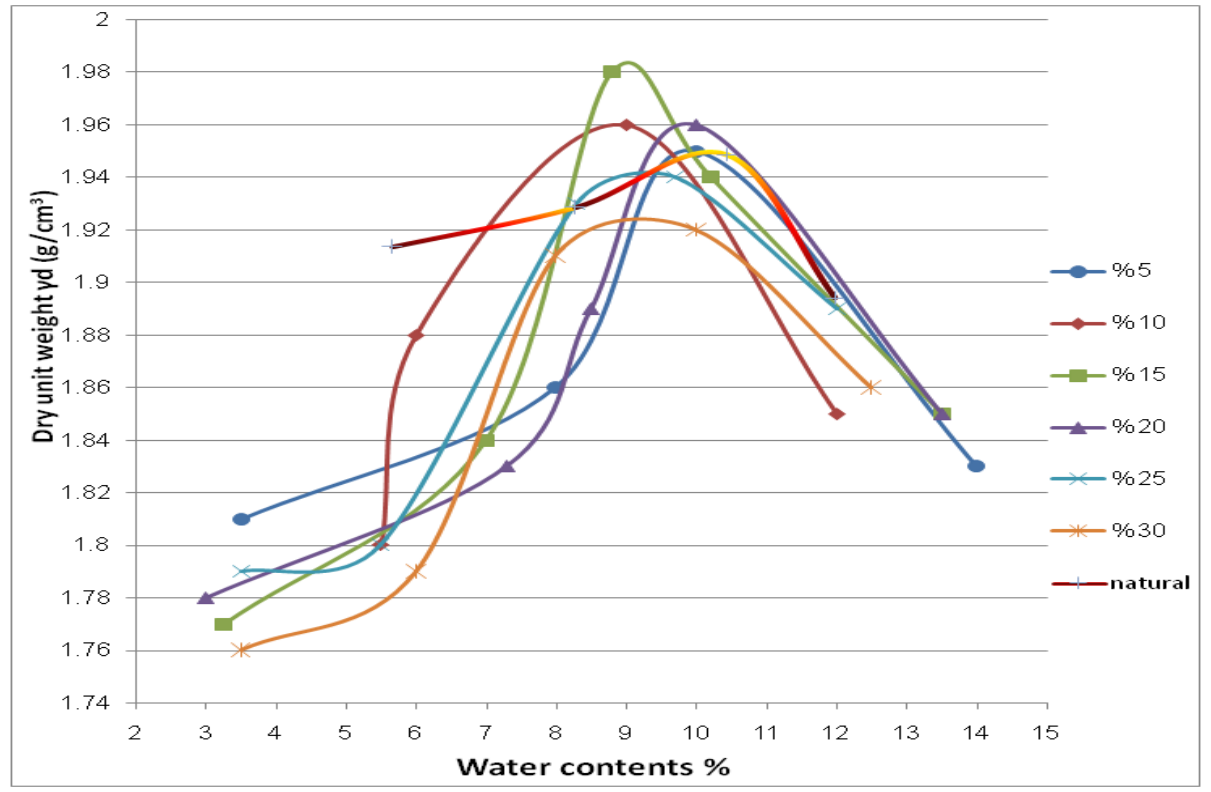

Figure 4: Standard Proctor Test Results on Soil With Various Lime Contents

Proceedings of First Conference for Engineering Sciences and Technology (CEST-2018), vol. 2 
The Effect of Adding Steel Slag and Lime on The Engineering Properties of a Sandy Soil

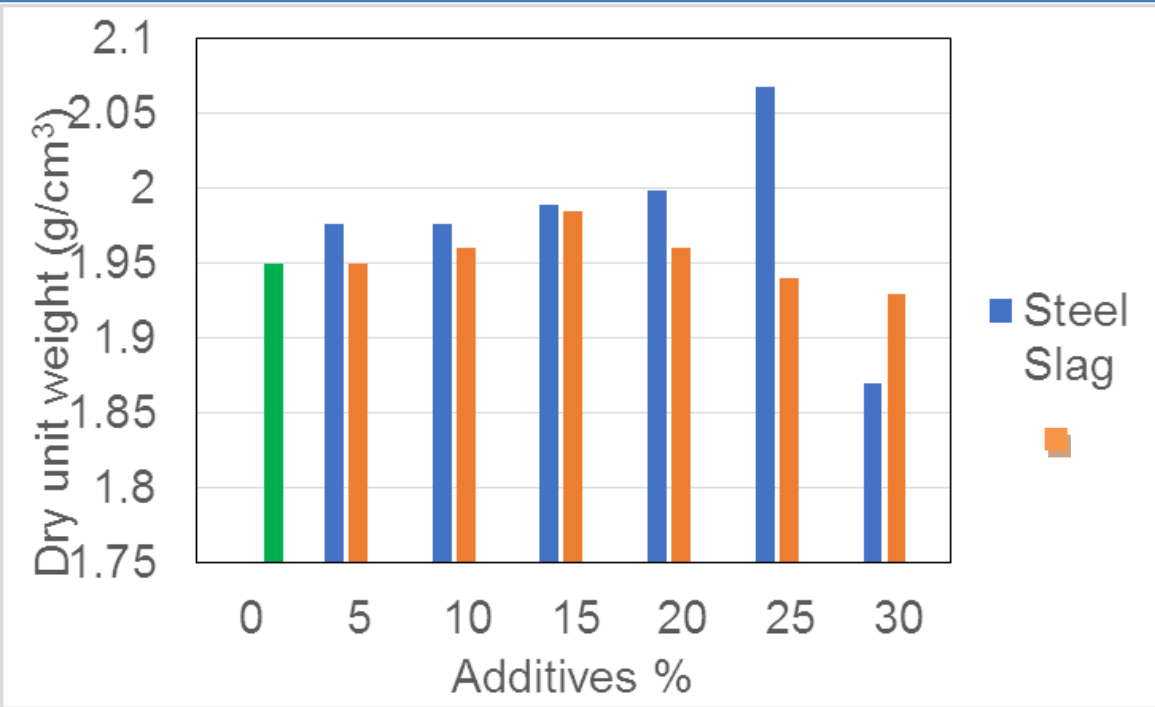

Figure 5: Comparison Between The Effect of Percentage of Additives on Maximum Dry Unit Weight

From Figure 6 it is obvious that the highest value of the optimum moisture content is obtained at natural soil , and the lowest at GGBS ratio (15\%).

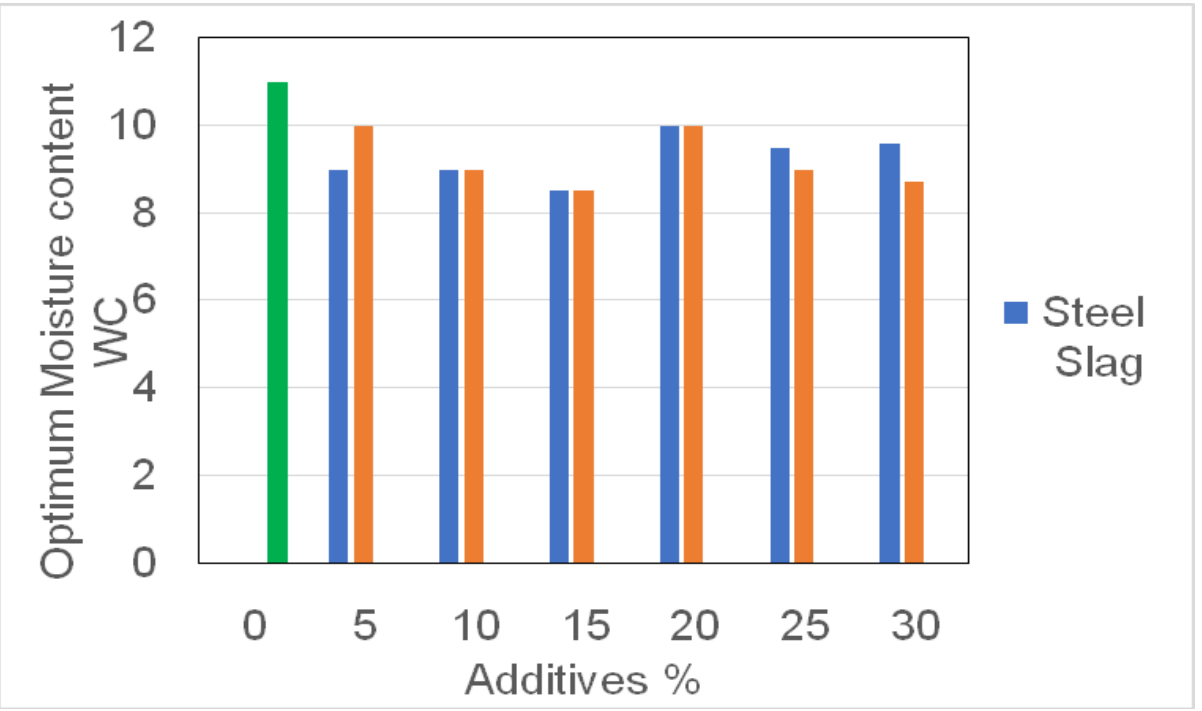

Figure 6: Comparison between the effect of percentage of additives on optimum moisture content

\section{Conclusions}

An extensive laboratory testing program was carried out to investigate the effect of addition of the steel slag and lime on the compaction characteristics of a sandy soil. The obtained results from both additives and were compared the following conclusions are made. The replacement of steel slag to sandy soil has a marked effect on the behavior of compaction of stabilized soil. The maximum dry unit weight increased gradually at the beginning of replacement of steel slag and the maximum dry unit weight increased by about $4.655 \%$ when 
Ayad et al., CEST-2018, AIJR Proceedings 4, pp.563-570, 2018

the steel slag content increased from $5 \%$ to $25 \%$. Increasing the steel slag content more than $25 \%$ (GGBS $>25 \%$ ) decreased the maximum dry unit weight, where steel slag content equal to $30 \%$ the maximum dry unit weight of treated soil decreased significantly by about $9.57 \%$ than that at $25 \%$. The optimum water content varied with steel slag content. the optimum water content fluctuated with the increase of steel content. The comparison between the effect of both replacement shows that steel slag is more effective than lime on the improvement of the max dry unit of the soil, while the effect of the both replacement on the OMC is almost the same at different used percentages. In addition of that steel slag has advantage of its low cost and easy availability in large quantities.

\section{Acknowledgment}

First and foremost, we thank Allah. This paper based on undergraduate project during the Academic year 2017/2018 done by the students, Abdelkader Hatim Abdelkader, Awad Zhran Awad and Abdalslam Musbah Alsdaiunder under the supervision of MSc. Ayad Abdelmoula Mohammed. The authors are gratefully and sincerely thank the students for their hard work on the experimental and theoretical parts of the project. Special thanks are due to Mr. Suliman Ahmed the technicians in the Soil Mechanics lab for his assistance with the laboratory work.

\section{References}

[1] Altun A, Yilmaz I, Study on steel furnace slags with high $\mathrm{MgO}$ as additive in Portland cement, Cement and Concrete Research, 32(8), (2002), 1247-1249, DOI 10.1016/S0008-8846(02)00763-9.

[2] Motz H, Geiseler J, Products of steel slags an opportunity to save natural resources, Waste Management, 21(3), (2001), 285293, DOI 10.1016/S0956- 053X(00)00102-1.

[3] Yildirim IZ, Prezzi M, Chemical, Mineralogical, and Morphological Properties of Steel Slag, Advances in Civil Engineering, 2011(2011), (2011), 1-13, DOI 10.1155/2011/463638.

[4] Akinwumi II, Adeyeri JB, Ejohwomu OA, Ee cts of Steel Slag Addition on the Plasticity, Strength, and Permeability of Lateritic Soil, International Conference of Sustainable Design, Engineering and Construction 2012, In: Chong WKO, Gong J, Chang J, Siddiqui MK (eds.), ICSDEC 2012, ICSDEC Conference Proceedings, American Society of Civil Engineers; Texas, United States, 2013, pp. 457-464, DOI 10.1061/9780784412688.055.

[5] K. Horii, T. Kato, K. Sugahara, N. Tsutsumi, and Y. Kitano, "Overview of iron and steel slag application and development of new utilization technologies," Nippon Steel and Sumitomo Metal Technical Report No. 1092015.

[6] J. Emery, "Steel slag utilization in asphalt mixes. National Slag Association, MF 186-1." Retrieved from www.nationalslagassoc.org, 1984.

[7] G. Singh, S. Sangwan, and M. Usman, "Experimental study of blast furnace slag concrete," International Journal of Engineering Sciences and Research Technology Experimental, vol. 9655, pp. 475-480, 2015

[8] K. J. Osinubi, A. O. Eberemu, and A. A. Amadi, "Compacted lateritic soil treated with blast furnace slag as hydraulic barriers in waste containment systems," International Journal of Risk Assessment and Management, vol. 13, pp. 171-189, 2009. View at Google Scholar | View at Publisher

[9] R. Oormila and T. V. Preethi, "Effect of stabilization using fly ash and GGBS in soil characteristics," International Journal of Engineering Trends and Technology, vol.11,pp.284-289,2014.

[10] H. D. Golakiya and C. D. Savani, "Studies on geotechnical properties of black cotton soil stabilized with furnace dust and dolomitic lime," International Research Journal of Engineering and Technology, vol. 2, pp. 810-823, 2015.

[11] I. Akinwumi, "Soil modification by the application of steel slag," Rperiodica Polytechnica Civil Engineering, vol. 58, pp. 371377, 2014. View at Google Scholar | View at Publisher.

[12] K. B. Biradar, U. Arun, and P. V. V. Satyanarayana, "Influence of steel slag and fly ash on strength properties of clayey soil : A comparative study," International Journal of Engineering Trends and Technology, vol. 14, pp. 61-64, 2014. View at Google Scholar | View at Publisher. 